\title{
RESISTENCIA, SUBSISTENCIA Y DIVERSIDAD EN LAS RIBERAS DEL RÍO MURU
}

\author{
Jesús José Diez Canseco Carranza ${ }^{1}$
}

ALBUQUERQUE, Gerson Rodrigues de. Trabalhadores do Muru: o rio das cigarras. Rio Branco (AC): Edufac, 2005, 171p.

El libro Trabalhadores do Muru, o Rio das Cigarrras de Gerson Rodrigues de Alburquerque (Edufac, 2005) se estructura partir de una investigación llevada a cabo en la Amazonía acreana, entre los trabajadores extractivistas y pequeños agricultores de las riberas del río Muru. A través de la pesquiza efectuada, se ponen en relieve las formas de vida y las relaciones (internas y externas) entabladas por los caucheros y ribereños de aquella zona en el período comprendido entre 1970 y 1990.

Teniendo como punto de referencia tal situación, el autor centra su mirada no sólo en las particularidades ligadas a la actividad económica de la región, sino que abarca aspectos, como el social y cultural, que son parte del quehacer cotidiano mismo de dichos pobladores.

Asimismo, se ponen en evidencia las estrategias o formas de lucha que estos trabajadores implementan con el fin de subsistir y adaptarse a los cambios que, vinculados a la expropiación, trastocan su hábitat físico y universo cultural.

El cuerpo del mismo, es decir, el segmento donde se desarrollan los aspectos más importantes, se divide en los siguientes tres capítulos: "Rios, Varadouros e Paranãs. Espaços de Experiência Huma$n a$ ". Aquí se tiene en cuenta y se presenta el marco físico-natural es decir el lugar donde los trabajadores desarrollan sus actividades, quehacers, formas de vida y relacionamientos, a partir de lo cual, en el día a día, moldean sus identidades. Del mismo modo se evidencian las secuelas y reacciones generadas, por estas personas, ante la irrupción traumática en su medio, de los grandes proyectos agropecuários; "Trabalho, identidade e luta social". Tomando como punto de partida las acciones llevadas a cabo por la empresa extrativista de caucho, el autor problematiza la relación entablada entre esta última y los trabajadores rurales; relación que se sustenta en hechos más bien punitivos-coactivos que despiertan en el hombre del seringal distintos mecanismos de resistencia y/o lucha; "Construçao de um Cotidiano Possiviel".- Este último capítulo constituye una invitación a la reflexión pues resalta las precarias formas de subsietencia y el duro trabajo que "nortean" la existencia de los sujetos estudiados. La realidad social que los envuelve no es para nada favorable y se ve "enturbiada" por las injusticias perpetradas por los patrones del barracón o aviadores en sus afán de mantener a su disposición la "mano de obra barata" por un lado y a clientes siempre endeudados, por otro. Esto ocasionaría la reacción de familias enteras y la gestación y consolidación de más de un movimiento social.

\section{BASES DE LA ARGUMENTACIÓN E INFLUENCIAS TEÓRICAS DEL AUTOR}

El autor fundamenta su investigación a partir de una metodología mixta que toma, fundamentalmente, métodos antropológicos como la etnometodología y la etnografía; linguísticos como los del análisis del discurso y pragmática y filosóficos como el fenomenológicohermeneútico.

En primer término dirige su mirada al paisaje natural y físico de los espacios intervenidos y, a partir de allí, escruta los modos de vida y relaciones que los sujetos- objeto de su estudio entablan. Luego, interesado en las distintas producciones de sentido de los pobladores de Tarauacá y, especialmente, aquellas vinculadas a la actividad extractivista, aplica entrevistas abiertas las que 
luego graba y transcribe. Como se observa, en un primer alcance, se vale de las técnicas y métodos del antropólogo, desarrollando, de este modo, una etnografía que da cuenta, como se acotó, de modos de trabajo, costumbres, relaciones, organización, etc. de los caucheros y sus familias y de un paisaje específico. Inmediatamente, despliega un especial interés etnometodológico pues centra su atención en los modos y estrategias comunicativos desplegados por los trabajadores caucheros (qué dicen - en realidad-, cómo lo dicen y en qué momento lo dicen?), rescatando los sentidos implícitos en las narrativas que conforman el sustrato cultural de esas comunidades.

Luego, tras transcribir las narrativas de las personas entrevistadas, analiza las discursividades que contienen el decir y sentir de aquéllas; generando un diálogo entre individuos, entre individuo y su hábitat, entre individuo y su coyuntura y entre individuo e investigador, lo que perfila situaciones sociales particulares como el percibir la mutabilidad perenne e inestabilidad de las realidades involucradas. De la misma manera, el autor hace hincapié en las formas comunicativas propias de los caucheros, las mismas que escaparían a las taxonomías rígidas y a las redes comunicacionales entretejidas en torno a la cultura dominante-occidental. Para ello, repara en los alcances de la pragmática linguística; a través de la cual dirige su interés, más bien, a los procesos vinculados al acto mismo de la enunciación y, no tanto, a los procesos abstarctos o intelectivos ligados a la producción (y teorización) del lenguaje. Aquí, además, entran a tallar algunos presupuestos sociolinguísticos pues se ponen en evidencia fenómenos linguístico-sociales cuya naturaleza contracultural o contra-hegemónica es muchas veces desestimada por los centros metropolitanos. De este modo, se rescatan los silencios, los gestos, ademanaes, proxémicas y demás formas comunicativas no verbales que tornan a la cultura de los caucheros en una cultura regida, principalmente, por los signos de la oralidad.

Asimismo, gracias a las técnicas de observación empírica y entrevista, y tras analizar las narrativas transcriptas, el autor de la pesquisa se introduce en ese universo cultural duro pero mágico, a veces, que enriquece la axiología y las relaciones entabladas por esos seres humanos. Del mismo modo, tras interpretar-develar los símbolos y sentidos contenidos en esas narrativas, se sumerge en el terreno de una afectividad o dimensión fenomenológica -siempre tensionada- que va desde la tristeza, la angustia, la impotencia, la rabia a los sentimientos de unidad, convivencia, religiosidad, resistencia y de búsqueda permanente de una dignidad que se muestra esquiva.

Dentro de los teóricos más citados, está el filósofo judeoalemán Walter Benjamin. Éste es un crítico pertinaz del progresismo (industrias culturales), del capitalismo, de las visiones del historicismo occidental y de todo aquello que atenta contra los modos tradicionales u originarios de existencia. También, menciona a los cultaralistas británicos Raymond Williams y Paul Thompson quienes, con sus categorías contraculturales, dan densidad epistémica a esta investigación. La propuesta dialógica de Mijail Bajtin aparece, también, a través de la objetivación de las múltiples relaciones linguísticas entabladas entre los sujetos del estudio y en la revalorización de una cultura popular gestada de espalda a las grandes urbes. Finalmente, puede percibirse la impronta del pensamiento de Stuart Hall "norteando" la tarea de rescatar y legitimar las prácticas de una cultura tenida, de manera arbitraria, por subalterna.

Con esto no se quiere decir que la investigación se restringe a los lineamientos teóricos mencionados. Ésta, por el contrario, abreva en otras propuestas que tornan a la misma en un 
documento adecuadamente respaldado. En tal sentido resulta pertinente enfatizar la veta postestructuralista existente pues conforme avanza la pesquisa se van desentrañado hechos, espacios y situaciones regidos o sustentados por una profusa red de relaciones. En este contexto, nada es estático, dichas relaciones varían permanentemente, tornando a los sujetos y espacios investigados, en unidades de análisis tan mudables e inestables como "un isótopo radiactivo".

\section{CONCLUSIONES DEL AUTOR}

Los sujetos de la investigación no retoman la vieja dicotomía rural vs. urbano. Ellos prefieren traducir una opción de vida vinculada al espacio natural y sus elementos; la relación con la naturaleza no sólo se desenvuelve como una estrategia de sobrevivencia sino como medio de lucha; la insurgencia de los caucheros, es también un medio a través del cual estos buscan afianzar su identidad; las comunidades ribereñas del río Muru no conforman agrupamientos monolíticos. Estos escapan a las propuestas racional-modernizantes presentes en los proyectos de integración o desarrollo regional; las formas de vida y trabajo de los caucheros del río Muru (y de las selvas amazónicas) son heterogéneas. Asimismo, las alternativas de sobrevivencia son cosntruidas por diferentes caminos. El diálogo entablado con las formas de vivir de estas personas no puede ser abordado de manera simplificada, es decir no se puede caer en reduccionismos y limitar realidades tan dinámicas al vacío del prejuicio, del estereotipo o de teorías deterministas.

\section{CONCLUSIONES PERSONALES}

A través del libro Trabalhadores do Muru, o Rio das Cigarrras se pudo constatar la valía y eficacia de la metodología cualitativa en los estudios de las distintas comunidades y de sus respectivas prácticas sociales. Del mismo modo, se pudo rescatar una propuesta que puede, también, llevarse y aplicarse a otros contextos. Si bien, las comunidades del río Muru son únicas e irrepetibles, pese a lo inestable que puedan resultar las estrategias para mantener y fortalecer sus identidades, esa misma naturaleza humana cambiante puede apreciarse en otras latitudes del continente latinoamericano en las que conviven, al unísono, gentes de temporalidaes, espacialidades, concepciones y contextos distintos y variables. Sin embargo, llama la atención que muchos estudios gestados en las academias metropolitanas no abreven en esa naturaleza variable y traten siempre de homogeinizar o encubrir ciertas prácticas o de rotular de "minorías" a grupos humanos cuya presencia es cada vez más notoria aunque no del todo reconocida.

Es importante, por tanto, tener en cuentas los aspectos relacionantes resaltados, los modos de generar identidad y las distintas modalidades comunicativas que un ser humano puede emplear con el fin de dejarse entender. Esto nos hace pensar si realmente vale la pena investirse de prescripciones, reglamentos y abstracciones cuando lo que se pretende es reconstruir universos culturales alternos y si realmente es pertinete evaluar, analizar, medir esos lenguajes (o praxis) con los instrumentos que solemos emplear en las ciudades, en las escuelas o universidades. A partir de acá, vale preguntarse si, realmente, los estudios oficiales llevados a cabo parten de concepciones estructuradas de antemano y sobre la necesidad de crear recursos y herramientas que nos aproximen lo más posible a esos universos que gravitan en torno a nosotros, sujetos citadinos, y establecer de modo concensuado los puentes que nos unan - por utópico que resulte - sin desnaturalizar o viciar por completo la esencia que subyace en nuestras prácticas, miradas, creencias y modos de relacionamiento.

Data de recebimento: 30/03/2016

Data de aceite: 10/05/2016 